\title{
Measuring the relative importance of strategic thinking dimensions in relation to counterproductive behavior
}

\author{
Afsaneh Zamani Moghaddam ${ }^{\mathrm{a}}$ and Faezeh Amirkamali ${ }^{\mathrm{b}^{*}}$
}

${ }^{a}$ Assistant Professor, Department of Management and Economy, Science and Research branch, Islamic Azad University, Tehran, Iran

${ }^{b}$ Master's graduate in EMBA, Department of Management and Economy, Science and Research branch, Islamic Azad University, Tehran, Iran

\section{H R O N I C L E}

\section{Article history:}

Received June 22, 2013

Received in revised format

28 August 2013

Accepted 21 September 2013

Available online

September 242013

Keywords:

Strategic thinking

Job performance

Organizational citizenship

behavior

Task behavior

Counter-productivity behavior

\section{A B S T R A C T}

\begin{abstract}
The purpose of this paper is to explore the relative importance of strategic thinking dimensions in prediction of counter-productive behavior. The research method is based on a descriptiveSurvey research. After collecting the questionnaires from 73 top managers and 110 staffs, the correlations between strategic thinking dimensions and counterproductive behavior were calculated. The relative importance method was used to calculate the relative weight of each dimension of strategic thinking in prediction of counterproductive behaviors. The results show that the strategic thinking of top managers is associated with their counterproductive behavior (correlation coefficient -0.38). Furthermore, The results of the Relative Importance Method indicate that the relative importance of each dimension of strategic thinking in prediction of counterproductive behavior is not the same. System perspective with $31.1 \%$ has the highest importance and hypothesis driven with $11.7 \%$ has the lowest weight. Intent focus, thinking in time and intelligent opportunism predict $14.1 \%, 13.3 \%$, and $29.8 \%$ of counter-productive changes, respectively.
\end{abstract}

\section{Introduction}

Nowadays, thinking power is one of the most powerful tools that every manager uses. Strategic thinking is referred to the process of creative and divergent thinking (Heracleous, 1998) and it plays an essential role in major issues of countries and organizations as well as personal decision making and planning. This is especially when this type of thinking is prevalent among middle managers throughout the organization and it may lead to efficiency and effectiveness improvements (Takur \& Calingo, 1992). According to Turner (1998), our ability to forecast the future is restricted. When the world is confronting with rapid and unpredictable changes without any control over crucial resources, many firms are not able to formulize and implement strategies. Therefor, "strategic thinking" is known as one of the most appropriate strategic approaches for most organizations. The ability to

*Corresponding author. Tel.: +98-912-362-4909

E-mail address: f.amirkamali@srbiau.ac.ir (F. Amirkamali)

(C) 2013 Growing Science Ltd. All rights reserved. doi: $10.5267 / \mathrm{j} . \mathrm{ms} 1.2013 .09 .025$ 
think strategically, however, is an essential item for remaining competitive in an increasingly turbulent and global environment (Bonn, 2001). Furthermore, these days, the "performance" has been one of the most popular research topics for organizational and industrial psychologists (Austin \& Villanova, 1992). Borman and Motowidlo (1993) recognized counterproductive behavior as one of job performance dimensions where employees create obstacles to the firm's performance (Rotundo \& Sackett, 2002).

Many researches have emphasized on the theoretical aspects and merits of strategic thinking, but few of them have studied the relationship between strategic thinking. In order to recognize the relative importance and priority of strategic thinking aspects influencing counterproductive behavior the "Relative Importance" method is used. Despite several researches on using such method in the field of strategic thinking, no result has been found and this could be the first application. In this research, "strategic thinking" and its aspects are considered as the predictor variable and "counterproductive behavior" as outcome variable. Therefore, the main objectives of this research are to explore the relationship between managers' strategic thinking and their counterproductive behavior as well as to determine the relative importance of strategic thinking dimensions in association with counterproductive behavior.

\section{Theoretical background}

\subsection{Strategic thinking}

Strategic thinking is associated with the process of creative and divergent thinking (Heracleous, 1998) and it is in association with the vision designed by the organization's leader. It requires managers to go beyond the ordinary functions and pay more careful attention to the long-term strategic intent of the organization. According to Stacey (1993), strategic thinking is "...using analogies and qualitative Similarities to develop creative new ideas... (and) designing actions on the basis of new learning". According to Mintzberg (1994), "strategy is recognized as one of the foremost advocates of strategic thinking, the term is not merely alternative nomenclature for everything falling under the umbrella of strategic management; rather, it is a particular way of thinking, with specific characteristics" (Liedtka, 1998).

There are several models, which represent dimensions of strategic thinking and the proposed model of this paper uses a model developed by Liedtka (1998), which is a particular way of thinking with specific attributes. Fig. 1 contains a model of the elements that she believes comprise strategic thinking.

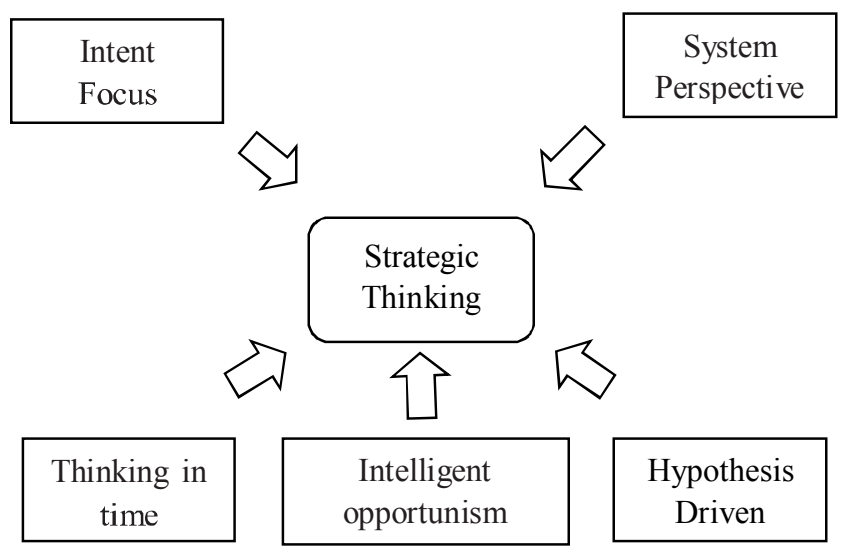

Fig. 1. The elements of strategic thinking (Liedtka, 1998) 


\subsubsection{System Perspective}

A strategic thinker is a mental model of the complete system of value creation from beginning to end, and understands the interdependencies within the chain. The systems perspective helps individuals detect their role within the larger system and the impact of their behavior on other parts of the system, as well as on the outcome. This approach addresses, therefore, not only the fit between the corporate, business, and functional levels of strategy, but also the person's level. From a vertical perspective, strategic thinkers see the linkages in the system from multiple perspectives and understand the relationship among the corporate, business, and functional levels of strategies to the external context, as well as to the personal daily choices they make. From a horizontal perspective, they also understand the connections across departments, functions, and between suppliers and buyers.

\subsubsection{Intent focused}

Strategic intent provides the focus, which allows individuals within an organization to marshal and leverage their energy, to focus attention, to resist distraction, and to focus for as long as it takes to achieve an objective. In the disorienting swirl of change, such psychic energy may well be the scarcest resource an organization has, and only those who utilize it will succeed. Therefore, strategic thinking is fundamentally concerned with, and driven by, the continuous shaping and re-shaping of intent.

\subsubsection{Intelligent Opportunism}

Within this intent-driven focus, there must be some place for intelligent opportunism, which furthers intended strategy and it means being responsive to good opportunities. The issues involved in using a well-articulated strategy to channel organizational efforts effectively and efficiently have to always be balanced against the risks of losing sight of alternative strategies better suited to a changing environment.

\subsubsection{Thinking in Time}

Strategy is not primarily driven by the future, but by the gap between the current reality and the intent for the future, by connecting the past with the present and linking this to the future, strategic thinking is always "thinking in time." This oscillation between the past, present, and future is essential for the execution of strategy as well as its formulation (Liedtka, 1998).

\subsubsection{Hypothesis driven}

The final element of strategic thinking recognizes it as a hypothesis-driven process. It mirrors the "scientific method", in that it deals with hypothesis generating and testing as central activities. Since it is hypothesis-driven, strategic thinking avoids the analytic-intuitive dichotomy that has Long Range Planning characterized much of the discussion on the value of formal planning (Liedtka, 1998). Strategic thinking is both creative and critical, in nature. Figuring out how to accomplish both kinds of thinking simultaneously has long troubled cognitive psychologists, since it is essential to suspend critical judgment to think more creatively (Paul, 1987).

\subsection{Counterproductive behavior}

Counterproductive behavior can be described as employee attitudes that intentionally hinder organizational goal accomplishment. The word "intentionally" is a key aspect of this definition; these 
are things that employees mean to do, not things they accidentally do (Colquitt et al., 2010). Counterproductive work behavior consists of a broad array of behaviors, which violate the firm's legitimate interests, including unsafe behavior and misuse of information, time or resources (Sackett \& DeVore, 2001). Rotundo and Sackett's (2002) defined counter-productive performance as "voluntary behavior that harms the well- being of the organization". The term counter-productive behavior has been broadly applied to capture actions deviating from social norms that, in the long run, detract from organizational effectiveness (Varela et al., 2010).

Although there are various kinds of counterproductive behaviors, they can be categorized into more specific categories (Fig. 2) (Robinson \& Bennett, 1995). Property deviance is associated with behaviors that harm the organization's assets and possessions. For instance, sabotage represents the purposeful destruction of physical equipment, organizational processes, or company products. Theft represents another kind of property deviance and can be just as expensive as sabotage. Research has indicated that up to three-quarter of all employees could be engaged in counterproductive behaviors such as theft, and the cost of these behaviors is considerable (Harper, 1990). Production deviance can also be directed against the firm but focuses more specifically on reducing the efficiency of work output. Wasting resources is the most common form of production deviance, when employees implement too much time to accomplish too little work.

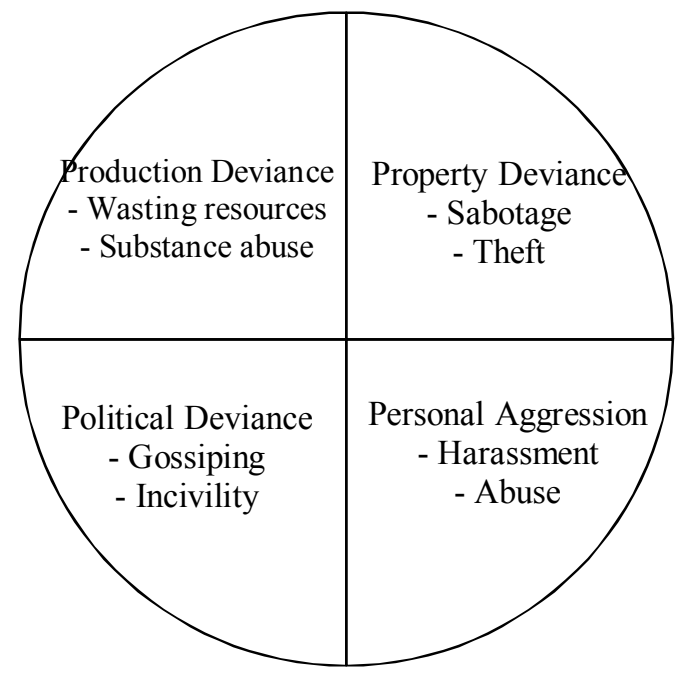

Fig. 2. Types of counterproductive behaviors (Robinson \& Bennet, 1995)

Substance abuse represents another form of production deviance when employees abuse drugs or alcohol while on the job or shortly before coming to work, then the efficiency of their production will be compromised because their work will be executed more slowly and less accurately.

In contrast to property and production deviance, political deviance is associated with behaviors that intentionally disadvantage other individuals rather than the larger organization (Andersson \& Pearson, 1999). The erosion of manners seems like a society-wide phenomenon, and the workplace is no exception.

Taken one by one, these political forms of counterproductive behavior may not seem specifically serious to most firms. However, in the aggregate, acts of political deviance can generate an organizational climate specified by distrust and unhealthy competitiveness. Beyond the productivity losses that result from a lack of cooperation among employees, most firms with this kind of climate likely cannot retain good employees. Moreover, there is some sort of evidence that gossip and 
incivility can "spiral" (Andersson \& Pearson, 1999). Those more serious interpersonal actions may involve personal aggression, described as hostile verbal and physical actions directed toward other employees. Harassment falls under this heading and happens when employees are considered to unwanted physical contact or verbal remarks from a colleague. Abuse also falls under this heading; it happens when an employee is assaulted or endangered in such a way that physical and psychological injuries may happen and it could cost organization, significantly (Colquitt et al., 2010).

Three points should be noted about counterproductive behavior. First, there is evidence that people who involve in one sort of counterproductive behavior also engage in others (Sackett, 2003).

In other words, such behaviors will more likely represent a pattern of behavior rather than isolated incidents. Second, like citizenship behavior, counterproductive behavior could be associated with any job. It does not matter what the job entails; there are things to steal, resources to waste, and people to be uncivil toward. Third, it is often surprising which employees engage in counterproductive attitude (Sackett \& DeVore, 2001). Sometimes the best task performers are the people who do their best to get away with counterproductive actions, because they are less likely to be suspected or blamed (Colquitt et al., 2003).

The research hypotheses are as follows,

$\mathrm{H}_{1}$ : There is a significant relationship between manager's strategic thinking and their counterproductive behavior.

$\mathrm{H}_{2}$ : The relative importance of strategic thinking dimensions in relation to counterproductive behavior is not the same.

\section{Methodology}

This study is a descriptive and analytic applied research. The survey technique was implemented for collecting the necessary data from the respondents. There are two target populations in this research; the first group is the top managers of Melli Bank of Iran in the city of Tehran. The number of this group by the use of census was set at 73 people. The second population is the direct employees of those top managers. The sample size of this group by the use of Cochran Formula was set at 110 people, and then the respondents were selected according to stratified random sampling.

In order to measure two variables of this research, two questionnaires are implemented, both using a 5-point Likert scale. The first one was distributed among top managers to measure their strategic thinking. The second one was given to the direct employees of those top managers in order to ask them about their managers' counterproductive behavior. The reliability of these questionnaires has been measured to be a Cronbach alpha of: 0.80 and 0.76 for strategic thinking and counterproductive behavior respectively.

Descriptive statistics i.e. frequencies, and valid percent were used to describe data. Spearman correlation test was also employed to determine whether or not there are significant relationships between strategic thinking as predictor variable and the counterproductive behavior as outcome variable. The data were analyzed using the statistical package for Social Science (SPSS). Then the Relative Importance method was used in order to measure the relative weight (importance) of strategic thinking dimensions, which predict counterproductive behavior. When inter correlation among predictors exists (as is the case in this study), regression coefficients have long been judged insufficient to indicate the relative importance of a predictor because the effect of one predictor cannot be considered when holding the other predictors constant (Budescu, 1993; Hoffman, 1962). The search for a meaningful index of the relative importance of predictors in multiple regressions has been going on for years. This type of index is often desired when the explanatory aspects of 
regression analysis are of interest. The authors define relative importance as the proportionate contribution each predictor makes to $\mathrm{R}^{2}$, considering both the unique contribution of each predictor by itself and its incremental contribution when combined with the other predictors (Johnson \& Lebreton, 2004).

\section{Results}

In our survey, $76.7 \%$ of the respondents were male, and $23.3 \%$ were female. The highest age group of respondents (69.6\%) includes those between 41-50 years and the smallest one is those upper 50 years (8\%). Over half of the participants have bachelor's degree $(52.4 \%)$ and $27 \%$ of them have MA and upper degree.

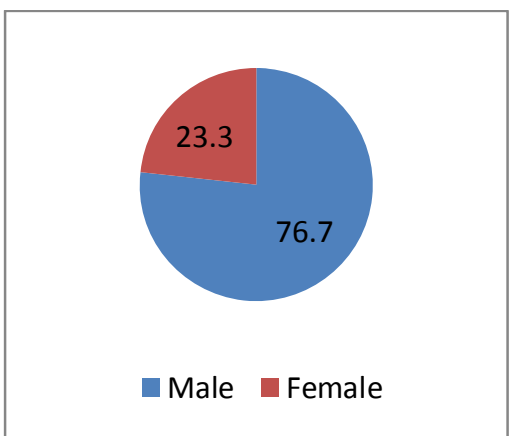

Gender

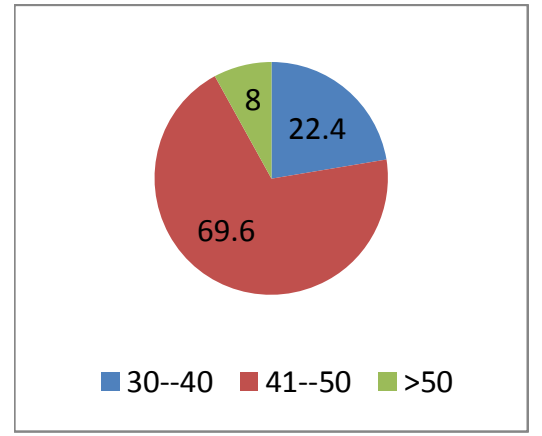

Age

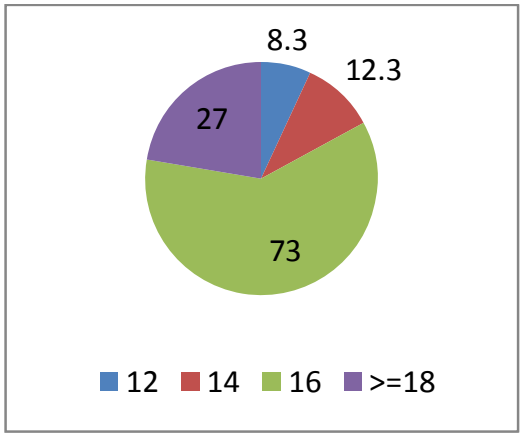

Years of education

Fig. 1. Personal characteristics of the participants

In the next stage, the hypotheses were studied. In order to find the correlation coefficient between strategic thinking and counterproductive behavior the Spearman correlation has been used.

Hypothesis 1. There is a significant relationship between manager's strategic thinking and their counterproductive behavior.

\section{Table 1}

Correlation between strategic thinking and counterproductive behavior

\begin{tabular}{|c|c|c|c|c|}
\hline & & & Strategic thinking & Counter-productive behavior \\
\hline \multirow{6}{*}{ Spearman's rho } & \multirow{3}{*}{ Strategic thinking } & Correlation Coefficient & 1.000 & $-.381 * *$ \\
\hline & & Sig. (2-tailed) & . & .000 \\
\hline & & $\mathrm{N}$ & 60 & 60 \\
\hline & \multirow{3}{*}{$\begin{array}{l}\text { Counter- } \\
\text { productive } \\
\text { behavior }\end{array}$} & Correlation Coefficient & $-.381 * *$ & 1.000 \\
\hline & & Sig. (2-tailed) & .000 & . \\
\hline & & $\mathrm{N}$ & 60 & 60 \\
\hline
\end{tabular}

As we can observe from the results of Table 1, strategic thinking significantly and under moderate related with job counterproductive behavior. Negative correlation was found between these two variables $(\mathrm{r}=-0.38)$. Top managers, who experience higher levels of strategic thinking, tend to have lower level of counterproductive behavior.

Hypothesis 2. The relative (importance) weight of strategic thinking dimensions in prediction of counter-productive behavior is not the same. 
First, the correlation between strategic thinking dimensions and counterproductive behavior was calculated. As can be seen from the results of Table 2 there are meaningful and positive relationships (correlation) between predictor (intent focus, system perspective, thinking in time, intelligent opportunism, and hypothesis driven) and outcome (counterproductive behavior) variable, and between predictor variables themselves. For instance, positive correlations were found between intent focus and thinking in time (0.893), intent focus and intelligent opportunism (0.905), intent focus and hypothesis driven (0.890).

Table 2

Correlation between strategic thinking dimensions and counterproductive behavior

\begin{tabular}{|c|c|c|c|c|c|c|c|}
\hline Research variables & & $\begin{array}{c}\text { Avoiding } \\
\text { counterproductive } \\
\text { behavior }\end{array}$ & $\begin{array}{c}\text { System } \\
\text { perspective }\end{array}$ & Intent focus & $\begin{array}{c}\text { Thinking in } \\
\text { time }\end{array}$ & $\begin{array}{l}\text { Intelligent } \\
\text { opportunism }\end{array}$ & $\begin{array}{l}\text { Hypothesis } \\
\text { driven }\end{array}$ \\
\hline \multirow{3}{*}{$\begin{array}{l}\text { Avoiding } \\
\text { counterproductive } \\
\text { behavior }\end{array}$} & Correlation Coefficient & 1.000 & $.543 * *$ & $.344 * *$ & $.265^{*}$ & $.419 * *$ & $.323^{*}$ \\
\hline & Sig. (2-tailed) & . & .000 & .007 & .041 & .001 & .012 \\
\hline & $\mathrm{N}$ & 60 & 60 & 60 & 60 & 60 & 60 \\
\hline \multirow{3}{*}{ System perspective } & Correlation Coefficient & $.243 * *$ & 1.000 & .080 & .094 & .250 & .152 \\
\hline & Sig. (2-tailed) & .000 & . & .542 & .473 & .054 & .245 \\
\hline & $\mathrm{N}$ & 60 & 60 & 60 & 60 & 60 & 60 \\
\hline \multirow{3}{*}{ Intent focus } & Correlation Coefficient & $.144 * *$ & .080 & 1.000 & $.893 * *$ & $.905^{* *}$ & $.890 * *$ \\
\hline & Sig. (2-tailed) & .007 & .542 & . & .000 & .000 & .000 \\
\hline & $\mathrm{N}$ & 60 & 60 & 60 & 60 & 60 & 60 \\
\hline \multirow{3}{*}{ Thinking in time } & Correlation Coefficient & $.105^{*}$ & .094 & $.893 * *$ & 1.000 & $.927 * *$ & $.950 * *$ \\
\hline & Sig. (2-tailed) & .041 & .473 & .000 & . & .000 & .000 \\
\hline & $\mathrm{N}$ & 60 & 60 & 60 & 60 & 60 & 60 \\
\hline \multirow{3}{*}{ Intelligent opportunism } & Correlation Coefficient & $.224 * *$ & .250 & $.905^{* *}$ & $.927 * *$ & 1.000 & $.889 * *$ \\
\hline & Sig. (2-tailed) & .001 & .054 & .000 & .000 & . & .000 \\
\hline & $\mathrm{N}$ & 60 & 60 & 60 & 60 & 60 & 60 \\
\hline \multirow{3}{*}{ Hypothesis driven } & Correlation Coefficient & $.080^{*}$ & .152 & $.890 * *$ & $.950 * *$ & $.889^{* *}$ & 1.000 \\
\hline & Sig. (2-tailed) & .012 & .245 & .000 & .000 & .000 & . \\
\hline & $\mathrm{N}$ & 60 & 60 & 60 & 60 & 60 & 60 \\
\hline
\end{tabular}

**. Correlation is significant at the 0.01 level (2-tailed).

*. Correlation is significant at the 0.05 level (2-tailed).

In the next stage, the relative importance weights were computed on the basis of Johnson's procedure. As can be seen in Table 3, results show that in prediction of counterproductive behavior, system perspective with $31.1 \%$ has the highest importance and hypothesis driven with $11.7 \%$ has the lowest weight. Intent focus, thinking in time, and intelligent opportunism predict $14.1 \%, 13.3 \%$, and $29.8 \%$ of counterproductive changes, respectively.

Table 3

The relative weight/importance of strategic thinking dimensions in prediction counterproductive behavior on the basis of Johnson's model

\begin{tabular}{llll}
\hline Strategic thinking dimensions & $\begin{array}{l}\text { The gross weight } \\
\text { of each dimension }\end{array}$ & $\begin{array}{l}\text { The relative weight of each dimension out of } 100 \% \\
\text { ( The gross weight/R2) }\end{array}$ & $\mathrm{N}$ \\
\hline System perspective & .046 & $31.1 \%$ & 60 \\
Intent focus & .021 & $14.1 \%$ & 60 \\
Thinking in time & .019 & $13.3 \%$ & 60 \\
Intelligent opportunism & .044 & $29.8 \%$ & 60 \\
\hline Hypothesis driven & .017 & $11.7 \%$ & 60 \\
\hline Total & $\mathrm{R} 2=.146$ & $100 \%$ & 60 \\
\hline
\end{tabular}




\section{Conclusions}

In accordance with the tested hypotheses, as the direction of correlation between strategic thinking and job performance was negative (0.48), so managers who enjoy higher level of strategic thinking tend to have lower level of counterproductive behavior. As well as this, results show that strategic thinking dimensions do not have the same weight (importance) in prediction of counterproductive behavior. The system perspective has the highest weight, and hypothesis driven has the lowest importance.

Since the system perspective has the highest weight in prediction of counterproductive behavior, and is the most important criterion in Liedtka's model too, it is suggested that top managers pay more careful attention to factors such as financial systems, informational and supportive systems, employees' efficiency, and global and local economic and political situation in the process of policy making; as well as this, allocating more time to analyze the competitors is advised.

\section{References}

Andersson, L.M., \& Pearson, C.M. (1999). Tit for Tat? The Spiraling Effect of Incivility in the Workplace. Academy of Management Review, 24, 452-71.

Bonn, I. (2001). Developing strategic thinking as a core competency. Management Decision, 39(1), 63-70.

Borman, W. C., \& Motowidlo, S. J. (1993). Expanding the criterion domain to include elements of contextual performance. San Francisco: Jossey-Bass.

Colquitt, J.A., Lepine, J.A., \& Wesson, M.J. (2010). Organization behavior: Essential for performance and commitment. Boston: Mc Graw-hill International.

Harper, D. (1990). Spotlight abuse - save profits. Industrial Distribution, 79, 47-51.

Heracleous, L. (1998). Strategic thinking or strategic planning?. Long Range Planning, 31(3), 481 487.

Liedtka, J. (1998). Linking strategic thinking with strategic planning. Strategy and Leadership, 26(4), 30-35.

Liedtka, J. (1998). Strategic thinking: can it be taught? Long range planning, 31(1), 120-129.

Mintzberg, H. (1994). The fall and rise of strategic planning. Harvard Business Review, 72(1), 107114.

Paul, R. (1987). Dialogical thinking: Critical thought essential to the acquisition of rational knowledge and passions, in: J. Baron and R. Sternberg (Eds.), Teaching thinking skills: Theory and practice.). W. H. Freeman, New York, pp. 127-148.

Robinson, S.L., \& Bennet, R. J. (1995). A typology of deviant workplace behaviors: A multidimensional scaling study. Academy of Management Journal, 38(2), 555-72.

Rotundo, M., \& Sackett, P. R. (2002). The relative importance of task, citizenship, and counterproductive performance to global ratings of job performance: A policy-capturing approach. Journal of Applied Psychology, 87, 66-80.

Sackett, PR., \& Devore, CT. (2001). Counterproductive behavior at work. London: Sage Publication. Stacey, R. (1993). Strategic thinking and the management of change. London: Kogan page.

Takur, M., \& Calingo, L.M. (1992). Strategic thinking is hip, but does it make a difference? Business Horizons, 48-54.

Turner, I. (1998). Strategy, Complexity and Uncertainty. Retrieved September 2012 from http://www.poolonline.com/archive/iss 1 fea5.html

Varela Otmar, E., Salgado Elvira, I., \& Lasio Maria, V. (2010). The meaning of job performance in collectivistic and high power distance cultures: Evidence from three Latin American countries. Cross Cultural Management Journal, 17(4), 407-426. 